\title{
RELAÇÕES DIALÓGICAS: COMPREENSÕES E ATITUDES RESPONSIVAS EM PRODUÇÕES ESCRITAS
}

\author{
SILVIO NUNES DA SILVA JÚNIOR ${ }^{1}$ \\ Universidade Federal da Bahia, Instituto de Letras \\ Programa de Pós-graduação em Língua e Cultura \\ Av. Barão de Jeremoabo, 147 - Campus Universitário de Ondina - 40170-115 \\ Salvador, BA - Brasil \\ junnyornunes@hotmail.com
}

\begin{abstract}
Resumo. Este trabalho tem como objetivo refletir sobre as relações dialógicas representadas pelas noções de compreensão e atitude responsiva ativa em produções escritas. No plano teórico, discuto sobre a noção de dialogismo, me embasando em textos oriundos do chamado círculo de Bakhtin, focalizando nos trechos que apontam indícios das noções já mencionadas. Em seguida, apresento uma análise discursiva sobre/da compreensão e da atitude (com base na ação) responsiva ativa, a partir de narrativas de vida e profissão, produzidas numa aula em cursos de pósgraduação lato sensu, atribuindo ênfase, para tanto, à posição do sujeito nas suas práticas de linguagem e ações profissionais.
\end{abstract}

Palavras-chave: dialogismo; círculo; sujeito.

\begin{abstract}
This work aims to reflect on the dialogic relations represented by the notions of understanding and active responsive attitude in written productions. On the theoretical level, I discuss the notion of dialogism, based on texts from the so-called Bakhtin circle, focusing on the excerpts that point to the notions already mentioned. Then, I present a discursive analysis of the active responsive understanding and attitude (based on the action), based on life and profession narratives, produced in a class in lato sensu graduate courses, attributing emphasis, to the position of the subject in his practices of language and professional actions.
\end{abstract}

Keywords: dialogism; circle; subject.

\section{Introdução}

Diversos estudos que lidam com a profissionalização (DASSOLER e LIMA, 2012; IAMAMOTO, 2015) apontam para a necessidade de um processo de autoobservação da prática profissional e reflexão contínua sobre a mesma. Nesse sentido, quando os olhares se voltam ao processo de formação acadêmica e complementar, essa questão se torna ainda mais restrita, isso porque a distribuição da carga horária, na maioria

\footnotetext{
1 Doutorando em Linguística Aplicada pelo Programa de Pós-graduação em Língua e Cultura da Universidade Federal da Bahia (PPGLINC/UFBA).
} 
das vezes, não condiz com as reais competências a serem desenvolvidas pelos profissionais em contexto formativo que é a instituição de ensino superior (IES) ${ }^{2}$.

Ao compreender a linguagem em seu caráter social, concreto e dinâmico (BAKHTIN, 2003, 2010), é natural a constatação de que existem relações que perpassam o tempo e o espaço ${ }^{3}$ dos profissionais em suas práticas de linguagem do dia-a-dia. Visto que essas relações estão intimamente voltadas para a constituição axiológica da linguagem (BAKHTIN, 1998 [1975]) ${ }^{4}$, elas possuem raízes sócio-históricas que se envolvem nas relações de poder, e nesse contexto muitas ideologias são constituídas, dadas, sobretudo, pela dialogia que permeia as práticas de linguagem. Com base nisso, vejo que as atitudes, que remetem às ações tomadas no ambiente de trabalho, resultam de compreensões e observações realizadas na prática profissional, bem como durante a formação.

Assim, as práticas de linguagem - orais e escritas - são fontes reais e fiáveis a ponto de demonstrar como e por meio de que são criadas atitudes ativas e táticas (DE CERTEAU, 2009) para a prática profissional de sujeitos em serviço, em quaisquer que sejam as áreas de atuação, como a educação, a saúde, a assistência social, dentre outras. Num ponto de vista dialógico, de linha bakhtiniana, observo que toda essa construção compactua com o que se conhece por responsividade. A responsividade representa um plano mais amplo no qual se inserem as noções de atitude e compreensão responsiva ativa, desenvolvidas a partir dos estudos do chamado círculo de Bakhtin ${ }^{5}$, na filosofia da linguagem.

Sob a ótica destas considerações preliminares, proponho, com este estudo, identificar os indícios de compreensão que levam a atitudes responsivas e ações ativas, por meio de narrativas de vida e profissão produzidas por profissionais/alunos de cursos de pós-graduação lato sensu (especialização) de uma IES de esfera privada de Alagoas, na qual atuei como docente da disciplina de Habilidades e Competências Profissionais na Contemporaneidade $^{6}$. Em primeiro plano, contextualizo teoricamente as noções de dialogismo e responsividade (atribuindo enfoque à compreensão e atitude responsiva), além de outros estudos que dialogam com esta mesma perspectiva de estudo da linguagem, para que, com isso, a análise seja mais significativamente entendida.

\footnotetext{
${ }^{2}$ Considero, neste estudo, a existência de profissões que não requerem formação superior. No entanto, os profissionais que colaboraram para esta pesquisa já possuem nível superior para exercerem as suas profissões.

${ }^{3}$ Ao pensar nas relações entre tempo e espaço na constituição de noções, lembra-se da noção de cronotopo (BAKHTIN, 1998 [1975]).

${ }^{4}$ Segundo Bakhtin (1998 [1975], p. 46), "um enunciado isolado e concreto sempre é dado num contexto cultural e semântico axiológico (científico, artístico, político, etc.) ou no contexto de uma situação isolada da vida privada; apenas nesses contextos o enunciado isolado é vivo e compreensível: ele é verdadeiro ou falso, belo ou disforme, sincero ou malicioso, franco, cínico, autoritário e assim por diante". Nesse sentido, a relação entre os enunciados e as situações sociais se estabelece a partir da entonação.

${ }^{5} \mathrm{O}$ Círculo de Bakhtin é constituído por uma equipe de estudiosos, na qual os integrantes principais são M. Bakhtin, o líder, V. N. Volochinov e P. N. Medvedev. Todos eles possuíam pretensões filosóficas comuns e se juntavam no intuito de debater os seus pensamentos, principalmente entre 1920 e 1930, na Rússia, período de grande produção intelectual do grupo (CLARK \& HOLQUIST, 1998 [1984]).

${ }^{6}$ As turmas de especialização em que atuei comportavam alunos de diversos cursos, uma vez que esta era em comum para todas as áreas e, por isto, seguia um ponto de vista multidisciplinar, cabendo ao docente realizar explanações e atividades que pudessem estimular os alunos a dialogarem sobre as suas mais diversas práticas profissionais.
} 


\section{DIALOGISMO, COMPREENSÃO E ATITUDE RESPONSIVA ATIVA}

Os estudos da linguagem em perspectiva dialógica já vinham dando breves indícios em textos aristotélicos. No entanto, foi na filosofia da linguagem, mais especificamente no chamado círculo bakhtiniano, que a concepção dialógica se expandiu e ganha destaque até a atualidade. De acordo com essa linha, a língua (e a linguagem em contexto amplo) se desenvolve como uma característica social e, dessa forma, está atrelada a um conjunto infinito de raízes sócio-históricas, numa interdependência de enunciados, uma vez que o que o $e u$ pronuncia deriva de um enunciado alheio e viceversa. Nesse sentido, a língua não é algo abstrato e homogêneo, nem tampouco situada num ponto de vista sincrônico; ela é uma construção social adquirida pelos sujeitos, isto é, é uma construção dialógica composta por um conjunto de ideologias.

Tudo o que é ideológico possui uma significação: ele representa e substitui algo encontrado fora dele, ou seja, ele é um signo. Onde não há signo também não há ideologia. Pode-se dizer que um corpo físico equivale a si próprio: ele não coincide inteiramente com a sua realidade única e natural. Nesse caso, não temos como falar de ideologia. (VOLOCHINOV, 2017, p. 92)

Em confronto com o estruturalismo linguístico, que defende a arbitrariedade ${ }^{7}$ do signo linguístico, o dialogismo considera que a arbitrariedade não existe no signo ideológico. Logo, se o objeto material não é visto com base na sua construção história e sociocultural, não será signo. Entretanto, não se elimina a possibilidade desse material se transformar em signo. Para tanto, "ele irá adquirir uma significação que ultrapassa os limites da sua existência particular" (op. cit, p. 93).

A natureza ideológica do signo se interliga a atividade mental do sujeito, a qual se torna responsável pela sua desenvoltura no todo social, pois é através da expressão que o sujeito se constitui. Além disso, "qualquer que seja o aspecto da expressão-enunciação considerado, ele será determinado pelas condições reais da enunciação em questão, isto é, antes de tudo pela situação social mais imediata" (BAKHTIN, 2010, p. 112). Sob essa ótica,

a atividade mental do sujeito constitui, da mesma forma que a expressão exterior, um território social. Em consequência, todo o itinerário que leva da atividade mental (o "conteúdo a exprimir") à sua objetivação externa (a "enunciação") situa-se completamente em território social. (BAKHTIN/VOLOCHINOV, 2010, p. 120)

Nesse sentido, a produção enunciativa do sujeito depende constantemente do conjunto de valores e ideologias com as quais ele tem contato na sua constituição, a partir da sua atividade mental. Pensando por esse ângulo, a enunciação tida como a objetivação externa do locutor está atrelada ao processo de produção enunciativa e compreensão dessa produção pelos seus interlocutores na interação, por isso que o estudo da linguagem, a partir do dialogismo, deve considerar as formas e os tipos de interação verbal em ligação

\footnotetext{
${ }^{7}$ Para Saussure (2006 [1916]), o signo linguístico é arbitrário. Ele é uma convenção social reconhecida pelos falantes de determinada língua. A arbitrariedade de dá, também, pela constatação de que não existe uma relação natural e pré-determinada entre significado e significante.
} 
com as condições concretas em que se realiza (BAKHTIN, 2010), conscientemente ou não, por intermédio de uma orientação social ${ }^{8}$.

[...] toda compreensão plena real é ativamente responsiva e não é senão uma fase inicial preparatória da resposta (seja qual for a forma em que ela se dê). O próprio falante está determinado precisamente a essa compreensão ativamente responsiva: ele não espera uma compreensão passiva, por assim dizer, que apenas duble o seu pensamento em voz alheia, mas uma resposta, uma concordância, uma participação, uma objeção, uma execução, etc. (BAKHTIN, 2003, p. 272)

Assim, quem produz o discurso espera ser respondido. Essa compreensão é basilar para o processo dialógico, pois a linguagem, como fenômeno concreto, social e dinâmico, carece ser construída diariamente por meio da enunciação, e esta só se torna possível se a compreensão dos interlocutores for responsiva ativa. Nesse contexto, a compreensão ativa sempre leva a uma atitude, a qual é mediada pelas práticas de linguagem, uma vez que "toda palavra serve de expressão a um em relação ao outro. Através da palavra, defino-me em relação ao outro, isto é, em última análise, em relação à coletividade" (BAKHTIN, 2010, p. 113). A atitude responsiva remete a uma ação situada. Dando continuidade a esse pensamento, Zozzoli (2002) traz o que chama de "produção responsiva ativa", observando que a partir de uma compreensão, o sujeito pode desenvolver uma nova produção discursiva.

Ainda no tocante à atitude responsiva ativa, observa-se que ela se materializa na linguagem como uma maneira de demonstrar a constituição não-estatizada das práticas sociais, sejam elas de linguagem ou não. De Certeau (2009) assinala que a linguagem é um lugar organizado que permite o desenvolvimento de diversas atividades. Na mesma corrente de pensamento, o autor compreende que, nessas atividades, o sujeito pode sobressair-se de redes de vigilância dispostas pelas relações de poder através de táticas. A tática é:

um cálculo que não pode contar com um próprio, nem, portanto, com uma fronteira que distingue o outro como totalidade visível. A tática só tem por lugar o do outro. Ela aí se insinua, fragmentariamente, sem aprendê-lo por inteiro, sem poder retê-lo a distância. Ela não se dispõe de base onde capitalizar os seus proveitos, preparar suas expansões e assegurar uma independência em face das circunstâncias. O 'próprio' é uma vitória do lugar sobre o tempo. Ao contrário, pelo fato de seu não lugar, a tática depende do tempo, vigiando para 'captar no voo' possibilidades de ganho. $O$ que ela ganha, não o guarda. Tem constantemente que jogar com os acontecimentos para os transformar em 'ocasiões'. [...] mas a sua síntese intelectual tem por forma não um discurso, mas a própria decisão, ato e maneira de aproveitar a 'ocasião'. (DE CERTEAU, 2009, p. 45)

Em diálogo com Bakhtin, De Certeau (2009) considera as raízes sócio-históricas dos signos ideológicos para explicar a diversidade de atitudes táticas que podem ser desenvolvidas pelos sujeitos. A tática, dessa maneira, pode ter um impacto simbólico em determinado contexto, ou, a depender de quem a desenvolve ${ }^{9}$ - incluindo toda a carga

\footnotetext{
8 “Quando a atividade mental se realiza sob a forma de uma enunciação, a orientação social à qual ela se submete adquire maior complexidade graças à exigência de adaptação ao contexto social imediato do ato de fala, e, acima de tudo, aos interlocutores concretos" (BAKHTIN/VOLOCHINOV, 2010, p. 120).

${ }^{9}$ Aqui se considera, principalmente, o processo de atividade mental do sujeito.
} 
intersubjetiva de signos ideológicos -, pode ter um impacto significativo; e é nessa perspectiva que se entende, também, a indissociável relação entre linguagem e sociedade e a ligação entre os discursos do eu com o outro.

Essa ligação pode ser encontrada em Bakhtin (2003), quando assinala que, na atividade de linguagem,

o enunciado é um elo na cadeia da comunicação discursiva e não pode ser separado dos elos precedentes que o determinam tanto de fora quanto de dentro, gerando nele atitudes responsivas diretas e ressonâncias dialógicas. Entretanto, o enunciado não está ligado apenas aos elos precedentes, mas também aos subsequentes da comunicação discursiva. Quando o enunciado é criado por um falante, tais elos ainda não existem. Desde o início, porém, o enunciado se constrói levando em conta as atitudes responsivas, em prol das quais ele, em essência, é criado. O papel dos outros para quem se constrói o enunciado, é excepcionalmente grande [...]. (BAKHTIN, 2003, p. 300-301)

Diante do que pontuei nesse tópico de discussão, fica claro que a compreensão e a atitude responsiva ativa, as quais fazem parte de um plano mais amplo denominado responsividade, se estabelecem enquanto relações dialógicas constantes na interação verbal e não-verbal dos sujeitos produtores de enunciados. A compreensão é sempre seguida de atitudes nas práticas de linguagem, sendo um aspecto determinante da interação oral e escrita dos sujeitos, pois cada enunciado é realizado num dado momento, o que o faz ser diferente de outros, mesmo que se materialize pelas mesmas palavras. Em outros termos, "[...] cada palavra se apresenta como uma arena em miniatura onde se entrecruzam e lutam os valores sociais de orientação contraditória. A palavra revela-se, no momento de sua expressão, como o produto da interação viva das forças sociais" (BAKHTIN, 2010, p. 48).

Tomando como base esses esclarecimentos, prossigo o estudo com uma contextualização sobre a atividade em sala de aula que propus para a coleta de dados. Os dados caracterizam-se pelas produções escritas dos alunos em forma de narrativas de vida e profissão.

\section{CONTEXTUALIZANDO A ATIVIDADE}

A proposta da IES em que ministrei a disciplina já mencionada nas considerações iniciais deste estudo é de que na parte presencial da mesma sejam desenvolvidas atividades que possam estimular os alunos a pensarem sobre as suas práticas, já que, com os cursos, todos objetivam gerar resultados mais satisfatórios em seus ambientes de trabalho. As disciplinas consideradas obrigatórias para todos os cursos são ministradas de forma semipresencial. Neste caso, no encontro presencial, dividi a disciplina em dois momentos (matutino e vespertino) ${ }^{10}$, para que, no primeiro, pudesse explanar as teorias multidisciplinares pautadas na profissionalização e palavras-chave relacionadas aos termos competência e habilidade, e no segundo fossem escritas produções escritas nas quais os alunos pudessem relatar alguma experiência exitosa que tiveram em ambiente de trabalho ou uma proposta de aprimoramento de alguma situação problema que costumam

${ }^{10}$ Como o período da manhã era mais extenso (4 horas) dediquei-o a explanação das teorias e discussão sobre elas. À tarde (duração de 2 horas e 30 minutos) fiz a explicação da atividade e solicitei as produções como requisito avaliativo. 
ter contato nos locais onde atuam. A partir da leitura dessas produções, num momento inicial, comecei a observar as relações dialógicas que permeavam cada uma das práticas relatadas pelos alunos em seus discursos, principalmente no tocante à compreensão e à atitude responsiva ativa.

\title{
RELAÇÕES DIALÓGICAS EM PRODUÇÕES ESCRITAS
}

Sabendo que a dialogicidade se concretiza na atividade social, a partir de uma concepção "tecida em conexão direta com sujeito, história, historiografia, sociedade, cultura, ética, estética, situação de produção, circulação e recepção" (BRAIT, s/d, p. 1), os processos de compreensão e atitude responsiva ativa, considerados, neste estudo, como relações dialógicas, se dão de forma natural. A linguagem como prática social é um aspecto que se encontra na exterioridade do sujeito. As relações dialógicas presentes nela se concebem numa naturalidade pela individualidade do discurso quando pronunciado por cada sujeito. Tendo como base os discursos orais e escritos, observo que por meio da escrita essas relações são ainda mais perceptíveis.

Destaco, primeiramente, na narrativa de uma professora o seguinte trecho para esta discussão:

\begin{abstract}
P: O público por mim atendido é composto por pessoas que não tiveram acesso a escola na idade correta. São cidadãos que tiveram seus direitos negados por algum motivo. Essas pessoas vêm para a sala de aula totalmente desacreditados, achando que não são capazes de aprender. As vezes vêm cansados pelo trabalho diário, pela idade, pela falta de incentivo da própria família e pela questão da cultura (muitas vezes ouço alunos dizendo que são velhos e não aprendem mais nada).
\end{abstract}

A partir do comentário da professora destacado em negrito, pode-se ver a compreensão responsiva ativa da professora para com as necessidades dos alunos, o que pode influenciar nas maneiras de abordar os objetos de ensino em sala de aula. Essa compreensão se dá através da linguagem num conjunto de signos ideológicos construídos sócio-históricamente (BAKHTIN, 2010); além disso, a palavra também estabelece uma ligação íntima com as ideologias, pois ela vem "sempre carregada de um conteúdo ou de um sentido ideológico ou vivencial" (BAKHTIN /VOLOCHINOV, 2006, p. 99; grifos dos autores). Tendo em vista que se trata de um recorte de um texto narrativo, em primeira pessoa, a situação de produção propicia uma maior desenvoltura ou até mesmo segurança do produtor/aluno na descrição fruto da sua observação no ambiente de trabalho.

Sob esse viés, é possível perceber que a professora, na narrativa, expõe o problema que é constante na sua prática, porém levanta as possíveis causas que levaram àquela realidade. Nesse sentido, pode-se ver uma maior abrangência da compreensão que ela faz sobre a sua sala de aula, principalmente por considerar a palavra do outro, o que leva, também, a uma compreensão maior de si enquanto profissional, neste caso, como professora da Educação de Jovens e Adultos (EJA). Assim, a atitude responsiva ativa pode ser encontrada como um resultado da compreensão quando ela diz que:

P: Existem sugestões importantes para mudar essa realidade, como o uso de metodologias que aproveitem a realidade do aluno como: sua história de vida, o contexto onde está inserido e através das vivências; isso faz com que o aluno se sinta capaz de participar das atividades onde o seu conhecimento seja valorizado. 
Mesmo compreendendo a realidade, ela entende que existem possíveis táticas para subverter uma realidade que não é historicamente situada, mas sim, faz parte de todo um contexto cultural que envolve a EJA no Brasil. Assim, a produção da narrativa pode ter servido para que ela observasse, de forma mais crítica, a sua prática e identificasse brechas para possivelmente melhorar uma realidade deficitária a partir da necessidade do aluno (outro). A relação dialógica referente a essa atitude responsiva ativa está na consideração da condição do outro, pois o dialogismo, em si, é constituído pelas experiências discursivas entre o eu e o outro (BRAIT, 2005) e, ainda, a interlocução dialogal entre falante e ouvinte se trata de uma ação ativa (MACHADO, 2005).

As experiências relatadas pela professora não especificaram os tipos de dificuldades que os alunos da EJA apresentam. Dentre as produções discursivas que se tem contato, geralmente está a de que os problemas relacionados à leitura e a escrita se dirigem diretamente ao professor. Entretanto, entre as alunas estava uma assistente social - num contexto de trabalho diferente da sala de aula - que relata as dificuldades na sua prática, visto que lida com pessoas que não dominam essas habilidades.

\begin{abstract}
AS: Sou assistente social e, por incrível que pareça, nos dias atuais existem jovens iletrados. Faço acompanhamento em uma criança que nasceu com microcefalia e o seu tratamento é contínuo. Semanalmente ela viaja para Maceió para dar continuidade com terapias ocupacionais. No município em que ela mora, faz seções com fonoaudióloga e outras consultas, aproximadamente 3 vezes por semana. [...]

A mãe é uma jovem de 20 anos que é quem acompanha a criança para tudo, devido o trabalho do pai, sendo que a mãe tem a ausência de habilidade de ler e escrever. Então ela fica muito dependente da nossa equipe de trabalho para qualquer coisa relacionada à criança e tem uma dificuldade enorme de entender as coisas, onde temos que explicar inúmeras vezes.
\end{abstract}

Antes de descrever o problema propriamente dito, ela contextualiza socialmente as "situações de produção" com as quais costuma ter contato no ambiente de trabalho. Com base nas suas primeiras palavras, dar-se a ver que a assistente social atende na rede pública de saúde, onde é obrigatório um acompanhamento mais efetivo para com o usuário, considerando que isso se dá por uma equipe multidisciplinar. A compreensão responsiva ativa da profissional para o caso relatado é justamente voltada à desenvoltura da mãe de uma criança especial no deslocamento semanal para a capital do estado onde reside, o que se interliga com as construções ideológicas que o sujeito faz, neste caso, na prática profissional. Essas ideologias, segundo Bakhtin, caracterizam-se pelas "diferentes formas de cultura, os sistemas superestruturais, como a arte, o direito, a religião, a ética, o conhecimento científico etc. (a ideologia oficial), e também os diferentes substratos da consciência individual" (PONZIO, 2008, p. 112-115).

A partir disto, ela destaca que:

\begin{abstract}
AS: Sempre tentamos ajuda-las e incentivamos a estudar, pois nunca é tarde para aprender e ela nos relata que já teve muitas oportunidades e não "aproveitou" devido a sua estrutura familiar, e hoje é seu maior sonho estudar devido o que vem passando tendo que enfrentar tudo isso e não tem condições, pois não tem com quem deixar a filha que necessita de cuidados especiais.
\end{abstract}


O posicionamento da profissional em relação às necessidades da mãe da criança especial demonstra o seu interesse em ajudar e, em perspectiva dialógica, concretiza o que Bakhtin/Volochinov (2006) considera quando diz que pela palavra o sujeito mostra interesse no objetivo. Isto é, a profissional mostra, pela palavra (a qual comporta o sentido linguístico $\left.{ }^{11}\right)$, a finalidade em se preocupar tanto com o desenvolvimento da criança enquanto sujeito basilar para o seu trabalho, como para a mãe que também precisa de cuidados mais atentos por não saber ler e escrever.

A atitude responsiva ativa vem comportando uma carga de ideologias de vida e profissão, uma vez que é partindo dessas e outras ideologias que o sujeito se constitui dialogicamente. Sobre isto, Volochinov (2017) assinala que "a conjunção entre as formas da língua e os temas ideológicos realizada na comunicação social (ou interação discursiva) compõem os signos ideológicos, que são responsáveis pela formação da personalidade interior e da consciência" (p. 56).

$\mathrm{Na}$ narrativa de um educador físico é possível observar problemas que dialogam com o que já expus com as outras produções, e ainda mais alguns:

EF: Dentro da minha área de atuação, a Educação Física na Saúde, existem diferentes tipos de dificuldades que costumo encontrar, sendo as principais: o analfabetismo; a falta de desenvolvimento motor adequado, devido à falta de estímulos corretos nas primeiras fases da vida; e a própria ignorância quanto aos cuidados básicos com o objetivo de manter o indivíduo saudável. $\mathrm{O}$ analfabetismo afeta negativamente nos casos onde há a necessidade de uma instrução ou cuidado se prescrevido de forma escrita, e a consequência disso é que, em determinadas ocasiões, a prescrição não é seguida fielmente dentro dos padrões adequados, podendo até trazer riscos à saúde daquele indivíduo. O desenvolvimento motor inadequado, devido a estímulos incorretos, influi principalmente na vida adulta, onde podem surgir problemas de origem postural, falta de equilíbrio e percepção de espaço, falta de coordenação motora, entre outros distúrbios que podem atrapalhar nas práticas que desenvolvo com os usuários, aumentando principalmente o risco de envolvimento de lesões.

Ao tratar especificamente de cada problema, a narrativa deste profissional dialoga com a da assistente social discutida anteriormente, principalmente quando se lembra das dificuldades de lidar com analfabetos e, além disso, acrescenta, em outras palavras, que isso está totalmente voltado a uma questão cultural. Faraco (2009) lembra que, no dialogismo, "todo dizer é, assim, parte integrante de uma discussão cultural (axiológica) em grande escala: ele responde ao já dito, refuta, confirma, antecipa respostas e objeções potenciais, procura apoito etc." (p. 59). Assim, com base nas ideologias que se constituem no seu ambiente de trabalho sobre a linguagem, mesmo não sendo em sala de aula, o faz considerar imprescindível o desenvolvimento das habilidades de leitura e escrita para (con)viver socialmente. Nesse processo de compreensão responsiva ativa sobre o cotidiano $^{12}$ (DE CERTEAU, 2009), "as relações dialógicas são possíveis também com a própria enunciação como um todo" (BAKHTIN, 2003 [1979], p. 211).

\footnotetext{
11 "O sentido linguístico de um determinado enunciado concebe-se sobre a base da linguagem, seu sentido real, sobre a base de outros enunciados concretos sobre o mesmo tema, outras opiniões, pontos de vista e apreciações em linguagens diversas [...]" (BAKHTINE, 1978, p. 104).

${ }^{12}$ Lembra-se a sociologia do cotidiano, na qual se enquadra De Certeau (2009) e suas análises. "As análises de Michel de Certeau sobre os discursos místicos - sem nunca tê-los confinados a interpretações reducionistas (históricas, sociológicas ou psicológicas) - permitiram ao autor pensar sobre esses "estranhos" como a contínua relação do mesmo com o outro (a alteridade) no teatro dos encontros humanos e de suas instituições aceitas" (SOUZA FILHO, 2002, p. 130).
} 
No que concerne à atitude responsiva e a ação ativa, ele afirma que:

EF: De acordo com as minhas experiências com o trabalho de educação, tanto de forma geral quanto em saúde, e o trabalho de educação permanente destinado aos profissionais das demais áreas são imprescindíveis para a melhora e manutenção da saúde da população.

Mesmo deixando de expandir mais especificamente a problemática discutida nas primeiras partes da narrativa, o profissional aponta para a educação permanente como forma de melhorar as questões levantadas por ele. Nessa linha de pensamento, entendese que a educação permanente relacionada ao analfabetismo é mais pautada na educação escolar. Já a educação permanente responsável pela questão da adaptação física envolve um conjunto de práticas multidisciplinares, nas quais o profissional da educação física se enquadra. Dessa forma, tanto o educador físico como os outros produtores das narrativas apresentaram as suas posições valorativas através da linguagem. "Essas posições valorativas são elementos essenciais à compreensão, pois, de acordo com o Círculo, na linguagem se revelam as valorações e ideologias do sujeito em relação ao objeto da enunciação" (SANTOS, 2015, p. 29).

Percebe-se que o jogo dialógico estabelecido nas narrativas de vida e profissão é responsável pelas diversas ações que permeiam o cotidiano profissional. Segundo Faraco (2009, p. 59), "todo enunciado é uma réplica, ou seja, não se constitui do nada fora daquilo que chamamos hoje de memória discursiva". É na memória discursiva que está situado todo o conjunto de enunciados orais e escritos pronunciados na atividade social enquanto conjunto ideológico de signos, visto que:

Nenhum signo cultural permanece isolado se for compreendido e ponderado, pois ele passa a fazer parte da unidade da consciência verbalmente formalizada. A consciência sempre saberá encontrar alguma aproximação verbal com o signo cultural. Por isso, em torno de todo signo ideológico se formam como que círculos crescentes de respostas e ressonâncias verbais. (VOLOCHINOV, 2017, p. 101)

Com essas reflexões, fica evidente a íntima relação da linguagem com as práticas sociais exercidas pelos sujeitos. Percebo, assim, que a linguagem vai além de um espelho da realidade e adensa num plano mais amplo em que a exterioridade é capaz de propiciar momentos de ressignificação de bases práticas e conceituais. Além disso, o elo dialógico estabelecido entre os discursos escritos com as reflexões teóricas apresentadas representa a manifestação das discussões de Bakhtin nos estudos sobre o dialogismo quando assinala a vida é dialógica por natureza, e viver faz parte deste diálogo.

\section{CONSIDERAÇÕES FINAIS}

Nesse estudo, busquei evidenciar particularidades do dialogismo, a partir de uma contextualização teórica, bem como de uma análise de produções escritas. Essa abordagem permite que se observem as práticas linguístico-discursivas que atribuem forma a criação dialógica mencionada em diversos estudos do círculo bakhtiniano. Vale lembrar, também, das formas de diálogo presentes no discurso escrito das narrativas de vida e profissão que analisei, em que os indícios da importante relação do locutor com os interlocutores foram apresentados a partir da dialogicidade que constitui a cadeia discursiva e ideológica. 
Os posicionamentos dos profissionais na escrita narrada retomam, em diversos momentos da análise, o sentido linguístico que transforma a palavra do discurso em enunciado concreto. Além disso, a partir desses enunciados, a compreensão responsiva ativa dos sujeitos remete à atitude responsiva e, ainda, para a ação ativa ${ }^{13}$. Menegassi e Fuza (2006) assinalam que a atitude responsiva pode se apresentar de forma interna ou externa. Ela é externa quando se escreve para que as pessoas vejam as ideias do autor e possam apresentar uma compreensão e uma resposta e, interna, quando a pessoa conversa consigo mesma sobre o texto que produziu, pois [...] responder ativamente é um processo de adaptação, de recriação, de transformação do que foi abordado diante de um contexto social imediato (STRIQUER, 2016).

No que tange a atitude responsiva, atribuí ênfase à interna, entendendo que é a partir da leitura de si que o profissional busca meios de aprimorar a sua prática, desenvolvendo sugestões para a prática de outros profissionais das suas áreas de atuação, etc. Portanto, ao finalizar esse texto, considero que as relações dialógicas estão em todos os lugares e são concebidas em todas as atividades de linguagem (em enunciados orais e escritos); além de que o estudo científico ainda tem um rico campo de pesquisa pouco explanado (os ambientes não escolares que dependem das práticas de linguagem), nos quais diversas relações dialógicas se cruzam e distribuem possibilidades pertinentes de estudos.

\section{REFERÊNCIAS}

BAKHTIN, M.M. Marxismo e Filosofia da Linguagem. 12a . ed. São Paulo: Hucitec, 2010.

Estética da criação verbal. Trad. Bras. 4a . ed. São Paulo: Martins Fontes, 2003 [1979]. Questões de literatura e de estética: a teoria do romance. Tradução do russo por Aurora F. Bernadini et. al. 4a. ed. São Paulo: Ed. Unesp; Hucitec, 1998 [1975].

BAKHTIN, M.M./VOLOCHINOV, V. Marxismo e filosofia da linguagem: problemas fundamentais do método sociológico na ciência da linguagem. 12a . ed. São Paulo: Hucitec, 2006 [1929].

BAKHTINE, M. Esthétique et théorie du roman. Paris: Gallimard, 1978.

BRAIT, B. Dialogismo e polifonia em mikhail bakhtin e o círculo (dez obras fundamentais). Disponível em http://fflch.usp.br/sites/fflch.usp.br/files/Bakhtin.pdf. Acesso em 02. out. 2017.

BRAIT, B; MELO, R. Enunciado/enunciado concreto/ enunciação. Em: BRAIT, B. (Org.). Bakhtin: conceitos-chave. São Paulo: Contexto, 2005.

CLARK, K; HOLQUIST, M. Mikhail Bakhtin (1984). Trad. de J. Guinsburg. São Paulo: Perspectiva, 1998.

DASSOLER, O.B; LIMA, D.M.S. A formação e a profissionalização docente: características, ousadia e saberes. Anais do IX ANPED SUL, p. 1-11, 2012.

DE CERTEAU, M. A invenção do cotidiano. $7^{\mathrm{a}}$. ed. Trad. Bras. Petrópolis: Vozes, 2009.

FARACO, C.A. Linguagem e diálogo: as ideias linguísticas do círculo de Bakhtin. São Paulo: Parábola Editorial, 2009.

IAMAMOTO, M.V. O serviço social na contemporaneidade: trabalho e formação profissional. 26 $6^{\mathrm{a}}$. ed. São Paulo: Cortez, 2015.

MACHADO, I.A. Gêneros discursivos. Em: BRAIT, B. (Org.). Bakhtin: conceitos-chave. São Paulo: Contexto, 2005. p. 151-166.

\footnotetext{
${ }^{13}$ A ação ativa já traz na etimologia dos termos um vínculo com as ações desenvolvidas pelos sujeitos em suas situações de trabalho.
} 
MENEGASSI, R.J; FUZA, A.F. A finalidade da escrita no livro didático: influências da imagem do interlocutor. Acta Scientiarum, (UEM), v. 28, 155-165, 2006.

PONZIO, A. A revolução bakhtiniana: o pensamento de Bakhtin e a ideologia contemporânea. Tradução do italiano por Valdemir Miotello. São Paulo: Contexto, 2008.

SANTOS, A.C. Linguagem e construção de sentido: o dialogismo como característica base da interação verbal. Revista Odisséia, v. 15, 18-30, 2015.

SAUSSURE, F. Curso de Linguística Geral. São Paulo: Cultrix, 2006.

SOUSA FILHO, A. Michel de Certeau: fundamentos de uma sociologia do cotidiano. Sociabilidades (USP), São Paulo, v. 2, 129-134, 2002.

STRIQUER, M.S.D. A responsividade em um curso de formação continuada docente. Revista X, v. 1, p. 1-12, 2016.

VOLOCHINOV, V. Marxismo e filosofia da linguagem: problemas fundamentais do método sociológico na ciência da linguagem. Tradução de Sheila Grilo. São Paulo: Editora 34, 2017.

ZOZZOLI, R.M.D. Compreensão e produção responsivas ativas: indícios nas produções dos alunos. Em: ZOZZOLI, R.M.D. (Org.) Ler e produzir: discurso, texto e formação do leitor. Maceió: Edufal, 2002. p.17-31.

Artigo recebido em: maio de 2018.

Aprovado e revisado em: setembro de 2018.

Publicado em: dezembro de 2018.

\section{Para citar este texto:}

SILVA JÚNIOR, Silvio Nunes da. Relações dialógicas: compreensões e atitudes responsivas em produções escritas. Entremeios [Revista de Estudos do Discurso, ISSN 2179-3514, on-line, www.entremeios.inf.br], Seção Estudos, Programa de PósGraduação em Ciências da Linguagem (PPGCL), Universidade do Vale do Sapucaí (UNIVÁS), Pouso Alegre (MG), vol. 17, p. 91-101, jul. - dez. 2018.

DOI: http://dx.doi.org/10.20337/ISSN2179-3514revistaENTREMEIOSvol17pagina91a101 